\title{
Article
}

\section{Supporting Young Elite Athletes With Mental Health Issues: Coaches' Experience and Their Perceived Role}

Lebrun, Florence, MacNamara, Aine, Collins, Dave and Rodgers, Sheelagh

Available at http://clok.uclan.ac.uk/32589/

Lebrun, Florence, MacNamara, Aine, Collins, Dave and Rodgers, Sheelagh (2020) Supporting Young Elite Athletes With Mental Health Issues: Coaches' Experience and Their Perceived Role. The Sport Psychologist, 34 . pp. 43-53. ISSN 0888-4781

It is advisable to refer to the publisher's version if you intend to cite from the work. http://dx.doi.org/10.1123/tsp.2019-0081

For more information about UCLan's research in this area go to http://www.uclan.ac.uk/researchgroups/ and search for <name of research Group>.

For information about Research generally at UCLan please go to http://www.uclan.ac.uk/research/

All outputs in CLoK are protected by Intellectual Property Rights law, including Copyright law. Copyright, IPR and Moral Rights for the works on this site are retained by the individual authors and/or other copyright owners. Terms and conditions for use of this material are defined in the policies page.

\section{CLoK}

Central Lancashire online Knowledge www.clok.uclan.ac.uk

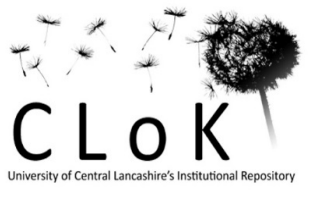


Supporting Young Elite Athletes with Mental Health Issues: Coaches' Experience and their Perceived Role

${ }^{1}$ Institute of Coaching and Performance, School of Sport and Wellbeing, University of Central Lancashire, Preston, Lancashire, UK.

$13{ }^{2}$ School of Health and Human Performance, Dublin City University, Ireland

$14{ }^{3}$ Moray House School of Education and Sport, The University of Edinburgh, Edinburgh, UK $15{ }^{4}$ Grey Matters Performance Ltd.

Running head: Coaches' supporting young athletes with MHIs

*Correspondence:

Prof. Dave Collins

25 E-mail: Dave.Collins@ed.ac.uk 
29 This study explored talent development coaches' experiences of athletes having faced mental

30 health issues. A second objective was to allow participants to share their opinion on how

31 sport environments could improve the support offered to coaches and athletes encountering

32 mental health issues. A thematic analysis was performed on eleven verbatim transcribed

33 interviews realised with UK-based talent development coaches. While monitoring and

34 supporting their athletes' performance and wellbeing was viewed as day-to-day practice,

35 dealing with mental health issues was, however, not considered as part of their role for a

36 variety of reasons. Findings also suggest that coaches need more a suitable and context-

37 specific knowledge and tools to appropriately respond and support their athletes. Generating

38 a better understanding of coaches' perceived role, knowledge, and needs to adequately

39 support their athletes suffering from mental health issues is crucial for the design of sport-

40 specific interventions and for the athletes themselves.

41 Keywords: thematic analysis, talent development, sport, mental health, coaching. 


\section{Supporting Young Elite Athletes with Mental Health Issues: Coaches' Experience and} their Perceived Role

A growing body of evidence illustrates that athletes, as with the general population, are subject to mental health issues (MHIs; Gouttebarge et al., 2018a; Rice et al., 2016; Roberts, Faull, \& Tod, 2016; Schaal et al., 2011). MHIs should not be conceived as merely the presence of psychopathology in the same way that mental health should not be defined as simply the absence of psychopathology (Henriksen et al., 2019; Keyes, 2005); this understanding is important as subclinical levels of mental disorders can negatively impact one's functioning and performance (Gouttebarge et al., 2018b; Gulliver, Griffiths, \& Christensen, 2012; Schinke, Stambulova, Si, \& Moore, 2017). Reflecting this, in the present paper, the term "MHIs" refers to a mental disorder and/or symptoms of psychological distress interfering with an individual's psychological state and usual activities, and is defined as: Signs and symptoms that impact how a person thinks, feels, communicates, or behaves. Some common symptoms of mental health issues include changes in a person's mood, changes in how a person interacts with others, and changes in how a person deals with daily stressors. A person with a mental health issue may find it difficult to complete tasks that are part of daily life (Livingston, Tugwell, Korf-Uzan, Cianfrone, \& Coniglio, 2013, p. 967).

Rather than the traditional focus on the prevalence of MHIs (Gouttebarge et al., 2018a; Gouttebarge, Kerkhoffs, \& Lambert, 2016; Wolanin, Gross, \& Hong, 2015), recent research has started to focus on the experience of athletes with MHIs (cf. Doherty, Hannigan, \& Campbell, 2016; Newman, Howells, \& Fletcher, 2016). Much of this research has focused on the experience of the athletes themselves without paying the same attention to the perspective of key stakeholders. Given the nature and importance of relationships in elite sport 
(Ringland, 2016), exploring mental health from the coach's perspective should provide important insights into the athlete's experience.

As a parallel issue, while interest in (elite) athletes' mental health and its impact on performance and wellbeing has rapidly grown (Rice et al., 2016; Schaal et al., 2011), less attention has been paid to young and developing athletes (Hill, MacNamara, Collins, \& Rodgers, 2016). Yet, young elite athletes involved in Talent Development (TD) environments (e.g., regional/national sport academies, national junior programmes) can train up to $15-20$ hours a week and compete early on in national and international youth competitions (Sabato, Walch, \& Caine, 2016). Like elite athletes, these young athletes commit their time and energy to competing at the highest level in their chosen sport and experience some success at that standard in their age category (ranging from under-13 to under-21; Sabato et al., 2016). The need to investigate MHIs in young elite athletes is particularly important since adolescence and young adulthood are known to be critical periods when it comes to the development and, perhaps even, prevention of MHIs (Kessler et al., 2005; MacNamara \& Collins, 2015). Due to the significance of the athlete-coach relationship (Jowett \& Cockerill, 2003) and the supportive role coaches can play in a young athlete's life (Gulliver et al., 2012; Mazzer \& Rickwood, 2015a), examining TD coaches' experience of working with young elite athletes facing MHIs is important, from both a research and applied perspective.

\section{The Contextual Backdrop}

Successful elite athletes (see Swann, Moran, \& Piggott, 2015) have to deal with both the stressors inherent to human life and the stressors and demands associated with their highpressured sporting life and career (MacNamara \& Collins, 2015; Schaal et al., 2011). Given the demands placed on athletes from an early age, young, developing athletes are also subject to a tremendous number of stressors as they progress on the pathway to elite status. In addition to the stressors that are characteristic of childhood (e.g., starting school, period of 
growth and development, family changes; Mental Health Foundation, 2016), adolescence (e.g., increased academic workload, changes in friendship groups, puberty, exam pressures; Mental Health Foundation, 2016), and young adulthood (e.g., transition to University or work; Mental Health Foundation, 2016), young elite athletes also face sport specific stressors and pressures.

The timing of the TD journey is, therefore, salient. Childhood and adolescence are atrisk periods for the first onset of MHIs (Kessler et al., 2005; Mazzer \& Rickwood, 2009), with about $10 \%$ of children (aged 5 to 16) in the U.K. experiencing MHIs (e.g., emotional disorders, anxiety disorders, conduct disorders, and attention-deficit/hyperactivity disorder; Green, McGinnity, Meltzer, Ford, \& Goodman, 2005; Kessler et al., 2005). The prevalence rate of MHIs is thought to increase during the adolescence (Green et al., 2005). $25 \%$ of young adults aged between 16 to 34 suffer from symptoms and/or disorders such as depression, anxiety, panic disorder, substance abuse, or eating disorders (Gulliver et al., 2012; Gulliver, Griffiths, Mackinnon, Batterham, \& Stanimirovic, 2015) - an age group that also corresponds to the peak competitive years for elite performers (Rice et al., 2016). This is even more important as MHIs in young people can have long-term effects which tend to carry on in later life (Mazzer \& Rickwood, 2009; Patel, Flisher, Hetrick, \& McGorry, 2007). Young developing elite performers may, therefore, be an at-risk cohort in relation to the onset of MHIs given their age and the additional sport-related stressors they experience (e.g., relocation, performance issues and injury; Gulliver et al., 2015; Rice et al., 2016). However, if MHIs can be caused or worsened by high-level sport participation (Reardon \& Factor, 2010; Roberts et al., 2016), it has also to be noticed that, in other cases, MHIs may have "nothing to do" with an athlete's sport participation whose athletic journey may continue unimpeded (Reardon \& Factor, 2010, p. 963). Likewise, for some athletes, sport participation is used a means to cope with pre-existing stressors or condition(s) (e.g., ADHD; Klinkowski, 
117 Korte, Pfeiffer, Lehmkuhl, \& Salbach-Andrae, 2008; Newman et al., 2016; Reardon \& Factor,

118 2010). Nevertheless, when negatively affecting young people's overall wellbeing and

119 personal development, MHIs may also lead to a derailment from the TD pathway (Hill,

120 MacNamara, \& Collins, 2015). Yet, despite the impact of MHIs on athletes' performance and

121 quality of life, young athletes are often reluctant to seek help (Gulliver et al., 2012). Young

122 athletes have, for example, been shown to have a relatively poor knowledge about mental

123 health and mental health services (Gulliver et al., 2012). The competitive nature of TD

124 environments has also been shown to exacerbate the social stigma associated with MHIs (e.g.,

125 "weak not sick"; Jorm \& Wright, 2008) and, as a consequence, athletes are often unwilling to

126 reveal any sign of vulnerability to others, especially coaches, teammates and competitors

127 (Gulliver et al., 2012; Mazzer \& Rickwood, 2009; Schaal et al., 2011).

128 Notably, when young athletes do seek help, they tend to solicit support and advice

129 from people they trust and are familiar and comfortable with such as coaches (Ferguson,

130 Swann, Liddle, \& Vella, 2018; Gulliver et al., 2012; Jowett \& Cockerill, 2003; Mazzer \&

131 Rickwood, 2009, 2015a). Indeed, in addition to their coaching role (e.g., training and

132 developing athletes' potential, instructing in relevant skills and providing encouragement), the

133 importance of the varied other roles of the coach, such as confidantes, role models and/or

134 mentors for their athletes (Ferguson et al., 2018; Jowett \& Cockerill, 2003; Mazzer \&

135 Rickwood, 2015a), is well supported in the literature. This presents a potential conundrum;

136 although coaches might not be the most qualified or suitable individuals to deal with MHIs

137 (Roberts et al., 2016), they have a role to play in facilitating the early detection of MHIs and

138 fostering subsequent help-seeking behaviours (Ferguson et al., 2018; Gulliver et al., 2012;

139 Mazzer \& Rickwood, 2015a). Due to their regular contacts with athletes over a prolonged

140 period of time, coaches seem well placed to notice any behavioural change(s) that may act as

141 warning sign(s) or symptom(s) of a MHI (Hill et al., 2015; Mazzer \& Rickwood, 2015a; 
142 Sebbens, Hassmén, Crisp, \& Wensley, 2016). Given that early detection and intervention has

143 been shown to lead to a better chance of recovery (Kamm, 2008), coaches seem well

144 positioned to enable the early identification of MHIs (Ferguson et al., 2018; Hill et al., 2015;

145 Hill et al., 2016; Mazzer \& Rickwood, 2015a), support their athletes' mental health needs

146 (Sebbens et al., 2016), encourage help-seeking behaviours (Gulliver et al., 2012), and refer

147 them to a mental health professional (if necessary). However, given the specificities of high-

148 performing environments and given that different sports are associated with different risks of

149 MHIs (Reardon et al., 2019; Rice et al., 2016; Schaal et al., 2011), it would be preferable that

150 such mental health professionals were knowledgeable in performance environments and in

151 that particular sport (Hill et al., 2015; Hill et al., 2016). Furthermore, despite their desire to

152 help and support their athletes' mental health, coaches must also recognise the boundaries

153 within which they (should) operate. As such, it is important that coaches acquire sufficient

154 knowledge about mental health and MHIs to be effective in this role (Ferguson et al., 2018;

155 Mazzer \& Rickwood, 2015a). Relevant knowledge about MHIs can aid the recognition,

156 management or prevention of MHIs (Lauber, Nordt, Falcato, \& Rössler, 2003). Therefore, the

157 ability to recognise early signs of MHIs or specific mental health disorders, and understanding

158 where to get further information and access professional help and treatment is an important

159 consideration for coaches (Lauber et al., 2003).

160 Reflecting these issues, the main purpose of this study was to investigate TD coaches'

161 experience of working with young elite athletes suffering from MHIs. We were also

162 interested in understanding the needs of TD coaches and TD environments in order to best

163 support TD coaches and their young performers. This in-depth investigation of coaches'

164 experiences and needs regarding MHIs should further inform the design of future

165 interventions and guidelines for health and sport professionals working in TD environments. 


\section{Philosophical Orientation and Design}

Given the aims of this study, a qualitative methodology was deemed the most appropriate approach as the objective was to better understand a phenomenon such as the

171 human condition in different contexts and situations (Bengtsson, 2016). At the same time, we

172 wanted to enable participants to freely share their experiences (Jones, Brown, \& Holloway,

173 2013). For this study, data were treated inductively through a thematic content analysis such

174 that the themes produced were closely linked to the data set (Braun \& Clarke, 2006). Patterns

175 of data were defined, examined and reported without these being embedded within any

176 established theoretical framework. Thematic analysis can be a realist or a constructionist

177 method (Braun \& Clarke, 2006). For the present study, a realist approach focusing on

178 participants' experience, meaning and reality was chosen (Braun \& Clarke, 2006). Whilst this

179 approach is realist and inductive, the themes were generated at a semantic level. Finally the

180 data analysis was driven by the data and not by the interview guide nor the researchers'

181 theoretical interest (Braun \& Clarke, 2006).

\section{Participants}

183 Through a network of personal and professional contacts, 11 coaches (two females and

184 nine males; Mean age $=42.55 ; \mathrm{SD}=11.13 ; \max =62$ years, $\min =30$ years $)$ working in $\mathrm{TD}$

185 environments were recruited to take part in this study. All participants were English speakers,

186 were coaching young athletes involved in TD environments and competing in an individual or

187 team sport (e.g., Football, Rugby, Hockey, Judo, Swimming, Athletics) within the U.K., and

188 were working or have worked in high-level TD environments for at least four years (Mean

189 working experience $=16.36 ; \mathrm{SD}=9.33 ; \max =30$ years, $\min =4$ years $)$. Most of the coaches

190 in the present sample had experience of working with various age groups (from under 8 years

191 old to $21+$ ) during their coaching career. Finally, all had, at some point during their career, 
encountered athletes experiencing MHIs. Information which might enable participants' identification is omitted or changed in order to ensure confidentiality to the participants and their athletes.

\section{Procedure}

Following ethical approval from the authors' university ethics committee, prospective participants received an invitation email that included an information sheet explaining the purpose of this project and inviting them to take part in the present study. Participants meeting the inclusion criteria and expressing an interest in taking part in this study were invited to contact the first author. Individual interviews were then organised at a convenient time and location. Prior to the beginning of each interview, participants were reminded of the aim of the study, that their participation was entirely voluntary, and all signed a consent form. Interviews lasted between 54 and 134 minutes (Mean 93.36; SD = 27.54), were conducted face-to-face, were recorded and transcribed verbatim.

Interview Guide. A semi-structured interview guide was used with all participants as a means to ensure consistency between the interviews. This interview guide was specifically created for the purpose of this study. The researchers used this guide to lead the interview and give the opportunity to the participants to share their experiences without restrictions (Jones et al., 2013). The interview guide contained questions enabling us to gain more insight into coaches' experience of coaching young elite athletes with MHIs. The interview started by inquiring on the participants' background in their sport. Following this introductory phase, a series of open-ended questions explored coaches' experience of MHIs in young elite athletes. These questions included:

1. Based on your experience, can you describe what kind of mental health issues athletes you coached have suffered from?

2. How did you learn about those issues? 
3. What have you done in each of those situations?

4. What have you learned from those experiences?

219 Probes and prompts were used to help participants to clarify and/or elaborate on their answers 220 (Jones et al., 2013).

Pilot study. Interviews were piloted with three participants (three males; Mean age $=$ 39; $\mathrm{SD}=9.54)$ matching the inclusion criteria. After the interview, these participants gave a feedback on the structure and content of the interview. Following their comments, no adjustment was deemed necessary to the interview guideline.

\section{Data Analysis}

Transcripts were analysed inductively by the first author through a thematic content analysis using Braun and Clark's (2006) step-by-step guide. This procedure allows the researchers to define, examine, and report patterns of data. To enable familiarization with the raw data, multiple active readings of each transcript were completed before starting the analysis (Braun \& Clarke, 2006; Jones et al., 2013). Coding was performed by use of a qualitative data analysis software (Nvivo 11; QSR International Pty Ltd., 2015). Initial codes were generated from the raw data and organised in meaningful units (Braun \& Clarke, 2006). Initial codes and sub-codes sharing a similar meaning were then brought together to generate common themes in relation to the phenomenon studied. Themes were then reviewed and refined into broader categories. This procedure was repeated until all meaningful units of raw data were ordered into the existing codes (Braun \& Clarke, 2006). Ensuing from this analysis, data were finally organised into higher order themes. Examples of codes and themes

238 will be reported in the results section by means of participants' quotes. To respect participants' confidentiality, no information enabling their identification will be reported and numbers will be used in the result section when mentioning participants' quotes. 
Trustworthiness. To assure the credibility and trustworthiness of the data, two

242 validation methods, peer-debriefing and member-reflection, were employed (Jones et al., 243 2013; Smith \& McGannon, 2017). After the analysis was conducted by the first author, the 244 data analysis and its ensuing codes and themes were individually reviewed by the second 245 author who had previous experience in qualitative methods. The first and second authors then 246 engaged in an open discussion about the development of the codes and themes, as well as the 247 interpretation that came out of it. The second author challenged the first one until a consensus 248 between the two was found while authors 3 and 4 acted as critical friends. This peer 249 debriefing process enabled all the researchers involved in the study to establish and then 250 critically share an understanding of the codes and themes generated (Jones et al., 2013).

251 Occurring throughout every stages of the present research, peer-debriefing process helped 252 guide the analysis and interpretation of the data (Jones et al., 2013). For member reflection (Smith \& McGannon, 2017), the themes obtained at the end of 254 the analysis stage were sent back, along with a brief description, to each participant who then 255 had the opportunity to reflect and comment on the researchers' interpretation of the findings 256 and themes generated from their transcripts. Seven participants out of eleven responded and 257 shared their feedback. While they all agree that the findings accurately represented their 258 views, a few offered some enriching reflections. Those reflections included, for example, the 259 importance of the club/academy policy regarding athletes' wellbeing, the impact of athletes' 260 age in regard to their understanding of what was happening to them, coaches' needs of 261 education, the need to have a multi-disciplinary approach to support athletes, and the 262 importance of good and open communication between all the protagonists (e.g., coaches, 263 players, parents, etc.). Once member-reflection and validation were completed, discussions 264 between the research team continued until a final agreement on hierarchical structure and 265 themes was reached (Jones et al., 2013). 
The purpose of this study was to examine TD coaches' experience of working with young elite athletes suffering from MHIs. Whilst participants in the present sample have worked, throughout their coaching career, with young athletes aged from 8 years old to $21+$, at the moment of this study, Coaches 2, 3,4 were predominantly working with athletes under 16 years old, whereas Coaches 1, 5, 6, 7, 8, 9, 10 were coaching athletes from 16 years old. Coach 11 was the only one coaching athletes from 8 years old to 21 years old. Over the years, participants had worked with performers facing a wide range of MHIs (e.g., from subclinical to clinical levels); these ranged from "issues" perceived as distressing (e.g., bullying, selfconfidence issues, anxiety, body dissatisfaction and disappointment) to clinically diagnosed disorders (e.g., depression, eating disorder, OCD, ADHD, psychotic episode). However, and given the amount of data generated from the participants' interviews, the following section will focus on three main higher themes identified in relation to the cases of MHIs reported; namely, coaches' perceived role when confronted with young elite athletes suffering from MHIs regardless of their severity, coaches' knowledge about MHIs, and the areas for improvements identified in order to improve the support offered to those athletes and their coaches in regard to MHIs. A summary of the themes is presented in Table 1.

TD Coaches' Perceived Role role of the TD coach is diverse with monitoring and supporting athletes' performance and wellbeing are being a big part of their everyday job. As explained by Coach 4: Monitoring and supporting young players is a massive part of the job. We are in the best position to get a picture of how the child is doing and to notice any changes in them. Particularly, when things are not going so well. There may be a number of 
reasons as to why that is the case and it is important that this information is shared amongst staff.

292 Gathering and Sharing Information. Monitoring their athletes over time allows coaches to 293 get a picture of what is happening for their athletes, to monitor their progress and to notice 294 any changes. When it comes to athletes' mental health, coaches can sometimes-learn about any potential problem via the athletes themselves - although this is not the most common route - or via a third party such as an athlete's teammates, their parents or another member of staff. The latter reportedly occurred especially when coaches have the chance to work within an interdisciplinary team (e.g., lifestyle manager, physiologist, nutritionist, doctor and sport psychologist). It is, however, predominantly through their regular contact with the athletes they coach and through their own observation that participants became aware of a mental health concern. As highlighted by Coach 6 in the following example: I think it would be through observation, through communication with the player. I'd suggest that in most cases it is observation, it is probably a tacit thing of having seen a very large number of boys, young men at that age. And also knowing that individual and knowing what their average behaviour is. And seeing how their body language and seeing how their training behaviour, how their behaviour generally changes. changes over time were some of the main indicators identified by the coaches, as warning signs. Given their regular interactions with their young athletes, the accumulation of changes from their performers' habitual pattern of behaviours particularly raised concerns - a point 311 reflected in the data as follows: It was about 4 years ago and the boy's behaviour, an outgoing boy really good fun, great to work with, got on with the job, very competitive in a football sense, and just a smashing lad to work with. All of a sudden, he became withdrawn. Didn't come up to 
you, when he turned up to training very quiet, totally different character. And I spotted this, and I thought you know 'He's not right, this is not right' ... we decided we'd monitor it and if we still thought that he wasn't improving we'd ask a question. So, nothing changed and the following week we said 'Are you OK, is there something

In a similar manner, Coach 4 described how: There was a change in his mood, a change in his attitude, a change in his application. Just a change in attitude. Change in level of performance, behaviour slightly changing. All those sorts of things were signs and indicators just saying to you something is not quite right. (Coach 4)

Once a concern had been raised, coaches working within an interdisciplinary team shared their concerns and information they might have about it with other relevant members of staff (e.g., lifestyle manager, physiologist, nutritionist, and psychologist) as two main goals - first, to draw a whole picture of the situation and, then, to come up with a plan on how to handle that situation; as typified by Coach 6: Very often we would work in an interdisciplinary manner ... So, we would have a weekly meeting to discuss how different players were going on, we would have a critical incident or a critical player bit at the start where we would discuss 'Right what's come up this week' and then we would also discuss other players who were on a regular cycle ... I think that very often it would be the sharing of concern within the staff group. That is then monitored. In whatever way that was. And then the decision was taken to, to seek further help, or not. Um, and in this particular case [concerns of OCD] it was monitored over a period of weeks. 
It has, however, to be noted that all the coaches interviewed did not have the same support

340 network at their disposal. Coach 8, for example, recognised that he "was privileged that I had a sport psychologist and I had a doctor. 99\% of coaches, 99.999\% of coaches don't have that,

342 they're on their own". Supporting this, Coach 11 explained that, in her case, sport 343 psychologists involved within her federation only worked on short-term contracts (in their 344 performance enhancing capacity). Only a few athletes (elite performers) had access to them. 345 Working predominantly with young aspiring elite athlete (from age 8 to 21), Coach 11, 346 therefore, did not have access to sport psychologists: ... at that time, the best they had was a lifestyle manager. They had a couple of different um sport psych's who seemed to do a little bit of work at the higher end with the elite lot but they, in fact [Sport Psych's Name] has done some and [ $2^{\text {nd }}$ Sport Psych's Name]. So, people you know but they've done some but each of them seems to have had a fairly, short-term role.

Coach 7 further stressed the variations in support staff available by describing how: When you get to a high enough level where there's the resources to do that, somebody is there to monitor the individual quite intensely as to what they're doing what they're not doing. Whereas at the levels below there isn't the resources to co-ordinate all that so 'yeah' I think that's a grey dangerous zone sometimes ... if the player wasn't a promising player, would the same support have been accessible? And we go back to that kind of sub-elite. So, when you're in an environment and the resources are there to pass them onto, it can be dealt with. But where you're in an environment where the resources aren't there - because either the sport isn't evolved enough to become a power sport or you're at a level that isn't quite. Then, would that support would have happened? So, within some squads you can have players on different levels of funding. So, if you're player A, and you have access to all the funding and have an 
issue, there'd be a mechanism there to support you. If you were player $\mathrm{C}$ with not the same amount of funding, because you're not perceived to be as high a potential. Supporting their Athletes. Caring and being supportive of their athletes is one of the biggest components of a coach's role and this was exemplified by many of the coaches when they described how "We [coaches] are duty bound to ensure that we look after them" (Coach 4). In this way, the coaches interviewed explained how they tried to emotionally support their athletes with MHIs by being understanding and tolerant, and showing they cared which mainly consisted in talking and listening to their players. As Coach 4 explained: example, coming up with a strategy with the staff members or/and with the child "so that he feels engaged, empowered, and part of the process, rather than removed from the process"

380 Coach 10). Besides, once aware of the existence of a potential MHI(s), monitoring those concerns more closely was a significant part of coaches' strategy as explained hereafter by

\section{Coach 7:}

I think that made me more sensitive to my players at the time who were of a concern to me, because the behaviours that I was hearing of in other environments I was more sensitive to monitoring in mine. And I tended to put some mechanisms in place where even though it wouldn't have looked like it, I was probably monitoring those issues ... So, without being intrusive I could keep an eye on some stuff. ... It was integrated in anyhow, it's part of our daily practice so the players never saw that as a change. So, I 
think the difference was that I introduced the mechanism for one reason, and that had been going on for a while. But then actually saw the same mechanism as another method to actually monitor some of the concerns.

392 Being flexible and able to adapt their coaching behaviours and expectations to particular

393 situations was another aspect of the coaching and informational support provided to their athletes. Interestingly, the coaches were aware of both the positive and negative impact they could have on their athletes' wellbeing and, as such, emphasized the need to be careful in regard to their coaching behaviours and practices. As Coach 3 reported:

I have to acknowledge that sometimes, I may have unwittingly caused or exacerbated the problem. For example, "if you don't start paying attention to us coaches, you won't last long at this club" interpreted as "I'm going to be chopped" with all the consequent anxiety.

Furthermore, when deemed appropriate, the coaches described how they would try to educate and increase their athletes' awareness about some common issues "through the nutritionist, through the psych. You know around healthy eating or body images or whatever it might be" (Coach 10).

Depending on the type of MHI(s), on its severity and on the context (e.g., what does the athlete want), coaches also provided tangible support. That form of support involved, as one example, removing the athlete experiencing MHIs from the sport environment [e.g., " $\mathrm{He}$ wanted to leave the environment and he had a free invite to come back in whenever he wanted to” (Coach 6)]. However, they all seemed to agree on the importance of involving qualified mental health professionals (e.g., doctor, psychologist). The reason to include a mental health professional was mainly twofold - firstly, as coaches, to get some help and advice on how to manage such a situation, but also to refer their athletes to a trained professional as clarified by the following example: 
I have worked with one player who we thought might be suffering from depression, and to be honest as soon as we got to that point where we became concerned, we got our Doctor involved, who I think to be honest then involved [Academy Psychologist's Name]. So, from a coach's point of view it was a bit, you know, that needs someone who is qualified for this. (Coach 1)

Coaches' Perceived Role Limits. While supporting their athletes was perceived as definitely part of a coach's role, all agreed that dealing with MHIs (e.g., having more than a supportive role) was not. All our sample recognised not being qualified nor trained to do so. They, therefore, preferred to pass it on to qualified professionals as illustrated below: I think something like that is so sensitive that unless you are qualified to deal with it, you can do more damage. I think it's sometimes recognising that you can't be the person who can fix it, and I wasn't that person. Because I think 'um', there is a level where expertise is needed, and you have to realise where your level of expertise is and

431 In addition, it was the participants' opinion that, in high-performance environments, coaches might not be the person an athlete would go to talk. Athletes' reluctance to talk about MHIs was kind of obvious for the present coaches and could, according to them, be explained by the

434 fear of the consequences of disclosing MHIs, MHIs being often considered as a sign of 435 weakness. In addition to the athletes' reluctance to talk about MHIs, participants mentioned the conflict of interest some of them could be subject to, from a coach's' perspective, when it came to MHIs and selection. Coach 7 described how: 
At the end of the day a Coach will always select or drop a player and therefore a conversation with a Coach is not always the best because they determine the outcome of selection. So even though sometimes you may want to help, you're never going to be perceived as that because ultimately you're going to be perceived as the person that There was a divergence of opinion, however, with Coach 1 suggesting that “... as a player you can feel you might be giving someone an excuse to drop you. I would never do that for uncomfortable situation they were in when making decisions about their team selection in regard to their funding was dependent on their athletes' and/or teams' performances. Coach

8, for example, explained that: It was pretty clear to me that if those athletes didn't perform then they would be out of the national centre and that I'd be joining them; I wouldn't be there either ... I think the positions that I have held have made it more difficult, you know I was the Head Coach of a national programme deciding whether people were in or out of national training centres but also whether they were gonna be funded or not funded. So, wearing 2 caps as a coach definitely challenged; a position for me as head coach of a national programme and also coaching TD was extremely difficult ... I think there was a level of an underlying tone in my later position of dishonesty through fear of what the repercussions of telling me what some issues might be.

\section{Coaches' Perceived Knowledge about Mental Health Issues}


463 MHIs varied across participants. One participant self-reported his knowledge and

464

understanding about MHIs as moderate whereas, ten participants out of eleven rated their knowledge as poor or limited [e.g., "quite poor knowledge I would say very poor knowledge" (Coach 5); “I'd probably say that it's still very limited, very basic” (Coach 7)]. This discrepancy between implicit and perceived knowledge and understanding about MHIs as demonstrated through their interviews might arise from the way those coaches acquired their knowledge.

Knowledge Acquisition. While a few gained some formal knowledge via lectures, readings, or workshops, most coaches in the present study acquired their knowledge over the years through their coaching experience, via the media or through personal experiences (e.g., family members, friends, own personal experience, etc.). Coach 11, for example, reported that:

I get mildly depressive. I have depressive issues. My Grandmother was on medication for years, but my father was a diagnosed manic depressive ... I have various experiences of mental health issues personally through family, and within sport I have come to realise there is a lot more happening for a lot more people than you might think on the surface. And so, there is a lot of learned experience and then through and somewhat with child development in my teaching degree, I have had some formal education with psychology. But very limited.

\section{Areas for Improvements}

Coaches' Identified Needs. Reflecting on their own experiences, coaches identified the need to increase coaches' and athletes' knowledge about mental health and MHIs in order "to have a better awareness of it, a better understanding of it and possibly be more ready for potential red flags" (Coach 1). They also highlighted the importance of having a professional 
network and support around them (e.g., doctor, clinical or sport psychologist) to support the athletes as much as possible but also to support the coaches and other staff members.

Increasing Coaches' Knowledge about MHIs. Most participants highlighted the need for coaches to increase their knowledge about MHIs but also for more guidance on what they should/can or should not/cannot do. As exemplified by Coach 5 in the following quote, they also described how they wanted to learn how to talk to athletes about MHIs and interact with those athletes in order to better support them.

... what do you say? And almost how do you open up in terms of trying to get him to open up ... what skills I would need? I think it's probably more of an awareness and how to maybe speaking to, if they are undergoing treatment how to dialogue with that person, which techniques to use when you're having those interactions, which techniques are they to use when I'm coaching, teaching. So, the biggest one would be the awareness and then you've got that backup, the backup would be that technique. Discriminating between "normal" behaviours or reactions and signs of MHIs was one of the biggest difficulties encountered by those coaches. While being able to spot red flags was considered as important, the participants acknowledged that they did not possess the necessary knowledge or confidence in regard to recognising MHIs. Indeed, even following an initial assessment of MHIs, the coaches acknowledged that they were unsure about the next course of action. Spotting red flags was particularly viewed as challenging for those coaches working with young athletes and adolescents- as exemplified by Coach 2 working with young athletes under 14 years old in the following quote.

Puberty's kicking in. There is all sorts of things going on 12s, 13s, so we look at them and think 'Ah yeah you know it's that, that's what's happening. And we allow for that. But sometimes, it could be something more serious ... For example, with the age of the players we deal with, and with so much going on in their lives, can we 
really identify what is a MHI as opposed to just growth or life issues. In fact, do people experiencing MHIs necessarily know they have them? Or, does better education on MHIs make people more likely to report them? Or be able to put a label on something which, in previous years was just feeling down at the moment."

In a similar manner, Coach 7, who has worked with a range of different age groups during her career, went further in regard to the education coaches would need and explained how for her: It is important to differentiate the ages of performers and how the approach to $\mathrm{MH}$ needs to be tailored to match the age ranges is essential. This in turn will influence the

mental health was not only deemed important for the coaching environment, but was felt to be an issue for the athletes themselves. As illustrated by Coach 9: I think education would be a useful thing for the athletes to sort of know that right potentially these are the stresses in life. So, certainly that kind of knowledge, so that athletes know. In the same way that they are given education in terms of anti-doping and stuff like that. You know what to take, what not to take, where are the sources to

In regard to athletes, the present participants particularly highlighted the need to not only increase their athletes' knowledge about MHIs (e.g., via the use of role models) but also 
giving them the means to cope. Coach 9, for example, clarified his earlier thoughts by explaining that: Just as I try to get them strong in a gym, I think we should also train the mind to be to work effectively for the athlete if you understand me 'yeah'? And if that takes training then train it ... I personally just do believe that in helping sports people to, provide them with coping skills I think that will help them to be better sportspeople but equally better people, human beings as well.

Risks of such Interventions. Although aware of the need to increase their understanding and knowledge, Coach 10 wondered if "Is that putting health that isn't needed, is that softening them because they don't? Do you get what I mean? Do they actually need it? Or is it just something that we react to once it shows its head?". Reflecting Coach 10's comments, seven other participants raised concerns about the risks associated with interventions targeting MHIs and mental health. One of the risks would be, for TD coaches, to become overcautious and see MHIs everywhere. As mentioned by Coach 3: There are normal ups and downs in life. I don't want to become paranoid with all the mental health issues and you going back on the field and saying 'Oh yeah' this one may have depression, this one may have eating disorders' no, that's not the point.

While other coaches, typified by Coach 8 , were afraid of the risks inherent in coaches' overconfidence in their own knowledge and abilities to deal with MHIs: I think a lot of damage can be done, you know, it's really at the forefront obviously mental health and if coaches are out there with a little bit of knowledge trying to help athletes with mental health issues that it could just be misdiagnose, you know, identifying things that aren't there.

Requirements for Sport Environments. Additionally, participants suggested the creation and implementation of a support network with health professionals, in particular, for 
those who do not already work within an interdisciplinary team as well as an increase in the

563 support (e.g., psychological support) available for both coaches and athletes.

Creation of a support network with health professionals. In addition to mental health interventions and due to the concerns raised in this regard, coaches emphasized the need to have an extended support network of health professionals (e.g., sport psychologist, clinical psychologist, nutritionist, doctor, etc.) available in the environment. This is even more important as such extended support networks seem to be rare in TD environments, as summarised by Coach 10:

It is down to the Club as a whole to decide what value it places on athlete's wellbeing and how it wants to support. Does it want to promote the support network, and utilize experienced staff to support players at varying times in their contracts and careers? ...There's no clinical psych linked to this club. There's a sports psych but he's got no clinical support mechanisms, where do we go? ... I'm not saying that every club should have a clinical psychologist aligned to them but what I am saying is that we should have an outlet for people that have clinical issues because none of us here are skilled enough to deal with it.

More support for coaches. Finally, in addition to more professional support for their athletes, some coaches highlighted the need for more support regarding their own mental health. Indeed, within the present sample, and as aforementioned, seven coaches out of eleven were exposed to one or more members of their family suffering from MHIs, while it was also noticed that five coaches experienced some MHIs themselves. Coach 8 , for example, witnessed that "depression within coaching is, is just as much if not more than it is within the athlete population". 

working with young elite athletes experiencing MHIs. A second objective was to determine coaches' and sport environments' needs in order to best support TD coaches and their young performers. The participants identified their role as varied but centred on monitoring and supporting their athletes' performance and health in various ways. Further to coaches' lack of knowledge regarding MHIs, they also noted the reluctance of athletes to talk about such issues with their coaches and the potential conflict of interest that might arise from such a situation. Finally, the coaches suggested that further support should be offered to coaches in regard to mental health as well as the development of a referral network within the sport that they could tap into in order to better support athletes with MHIs.

597 wellbeing were seen as central to the role of a TD coach. Although differentiating between 598 signs of MHIs and normal range of reactions or feelings to adverse events can be difficult 599 (Cornford, Hill, \& Reilly, 2007; Gulliver et al., 2012), coaches seem well positioned to notice 600 red flags such as any accumulation of, and persistent changes in, their athletes' behaviours 601 and/or performance over time (Hill et al., 2016; Lebrun, MacNamara, Rodgers, \& Collins, 602 2018) due their regular interactions with their athletes. Once mental health concerns have been raised, coaches are well placed to provide support (e.g., emotional, informational, and/or

604 tangible support) and promote help-seeking behaviours in order to prevent the development or 605 the exacerbation of a MHI (Ferguson et al., 2018; Mazzer \& Rickwood, 2015a). However, as 606 found elsewhere in the literature (Ferguson et al., 2018; Mazzer \& Rickwood, 2015a), TD 607 coaches in this study did not believe that dealing with MHIs was part of their role. 608 Furthermore, and unlike previous studies where coaches reported a confidant role due to their 609 established, trusted relationship and familiarity with their athletes (Ferguson et al., 2018; 610 Gulliver et al., 2012; Jowett \& Cockerill, 2003; Mazzer \& Rickwood, 2009, 2015a), our 
611 participants reported a reluctance on the part of their athletes to talk about MHIs with them as

612 well as a reluctance on the part of coaches to intervene due to a lack of understanding of the

613 phenomenon, a fear of the consequences of initiating such discussion as well as potential

614 conflict of interest arising from their performance role as a coach. Despite a divergence of

615 opinion in this regard, some coaches acknowledged some difficulties juggling with being

616 both a coach and a selector or head coach. The potential conflict of interest highlighted in

617 these situations was more likely determined by the way funding was allocated to those

618 coaches and/or sports (e.g., depending on athletes' and/or team's performances). More

619 research is warranted in regard to the conflict of interest TD and elite coaches may face when

620 working high-performing athletes suffering from MHIs.

621 While it might be expected that TD coaches would hold more information about mental

622 health than community levels coaches (Ferguson et al., 2018), participants in the present study

623 identified their knowledge and understanding about MHIs as limited and insufficient. The

624 detection of early signs of MHIs can be challenging. Accordingly, coaches recognized the need

625 to increase their knowledge and understanding about mental health and MHIs to be effective in

626 their role (Ferguson et al., 2018; Mazzer \& Rickwood, 2015a). Targeting coaches' knowledge

627 and understanding about mental health and MHIs may help them better assist their athletes by

628 acquiring the "ability to gain access to, understand, and use information in ways which promote

629 and maintain good mental health" (Lauber et al., 2003, p. 248). It could also, in return,

630 encourage their athletes to talk to them given that young elite athletes' perception of their

631 coaches' literacy influences their willingness to talk to or seek support from them about MHIs

632 (Swann et al., 2018). Similarly, interventions promoting mental health (e.g., knowledge,

633 attitudes, support available and skills) could also be offered, in parallel, to those young athletes

634 and their family as a way to provide them with a holistic support package (Hill et al., 2016) and

635 help to prevent young and promising athletes with MHIs to derail from their TD pathway. 
637 knowledge and understanding about mental health and MHIs, participants also highlighted the 638 potential risks of such an approach. They not only emphasized the importance of adapting 639 mental health interventions to meet their needs and their athletes' particular needs by stressing 640 the importance of quality and specificity (e.g., sport, age) in the delivery of any intervention. 641 Therefore, in line with Liddle et al.'s (2017) recommendation, coaches stressed the importance 642 to carefully identify the content, format, audience and outcomes targeted by mental health 643 interventions. Context-specific mental health training (e.g., sport- and age-related), specially 644 designed for TD and elite sport environments, might, for example, be of interest, especially as 645 symptoms (Doherty et al., 2016) and prevalence of certain type of MHIs can differ from one 646 sport to another (Rice et al., 2016; Schaal et al., 2011). Interventions targeting coaches' mental 647 health knowledge and awareness should aim to empower them with adequate knowledge and 648 skills to fulfil their supportive role (e.g., emotional and information support, referrals options 649 and confidence in their competences; Mazzer \& Rickwood, 2015a; Swann et al., 2018) while, 650 at the same time, addressing the operationalisation of the support provided (e.g., "what do you 651 say?", challenge versus support) and their concerns in such situation (Mazzer \& Rickwood, 652 2015b).

653 In addition to increasing coaches', athletes', and staff members' knowledge and 654 understanding about mental health, participants also highlighted the advantages of working as 655 part of an interdisciplinary team. In this regard, some of the participants described how the 656 interdisciplinary makeup of the staff within their clubs or academies, and their access to 657 medical and/or psychological expertise (e.g., club doctor, sport psychologist), was seen as an 658 advantage in the detection of MHIs as well as in the support provided to them and their 659 athletes. Working as an interdisciplinary team (including health professionals such as sport 660 psychologist, clinical psychologist, nutritionists, physiotherapists) by recognizing the unique 
661 skills set of each member and the benefits of working in an integrative approach (Kamm,

662 2008; Reardon et al., 2019) is especially valuable as it can aid the early detection of

663 psychological distress and provide better (proactive and retroactive) support to those

664 concerned (Gouttebarge, Backx, Aoki, \& Kerkhoffs, 2015; Gouttebarge et al., 2018b). Yet,

665 not all environments have the opportunity to hire multiple specialists interacting with each

666 other. There is, therefore, a need to develop and implement a referral network that coaches

667 can access for support (e.g., advice) and referral. The ethical implications of such actions will,

668 however, need to be considered in much greater depth (e.g., confidentiality, excpectations;

669 Anderson \& Pierce, 2012; Roberts et al., 2016). Finally, athletes are not the only one that

670 require assistance. As stressed by the participants, coaches need help and support to care for

671 their athletes but also vis-à-vis their own mental health. Unfortunately, while the literature on

672 athletes' mental health is growing (cf. Doherty et al., 2016; Gouttebarge et al., 2015;

673 Gouttebarge et al., 2018a; Kamm, 2008; Rice et al., 2016), studies looking into coaches'

674 mental health are still lacking. Further research is, therefore, warranted on TD and elite

675 coaches' mental health.

676 This study has important implications for the role of TD coaches in supporting young elite

677 athletes experiencing MHIs, and for how TD sport environments could better assist and

678 support their coaches working with athletes with MHIs. However, the present study was not

679 without limitations and findings must, therefore, be interpreted with caution. Firstly, given the

680 methodology employed, some memory recall issues might have impacted the results as it is

681 often the case in retrospective studies. Another issue raising from any qualitative approach is

682 the social desirability that might impact the results given the sensitivity of the present topic.

683 Participants might have overvalued or undervalued their role or the support they perceived

684 having offered to their athletes experiencing MHIs. The findings must, therefore, not be

685 viewed as an exact 'at the time' recollections of events and actions. Furthermore, participants 
686

687

688

689

690

691

692

693

694

695

696

697

698

699

700

701

702

703

704

705

706

707

708

709

710

varied in terms of diversity and types of sports (individual or team sports), career length, gender, and coaching age-group, factors that could have influenced their experiences of athletes with MHIs (e.g., in terms of type and number of MHIs cases experienced during their career). The chosen population, the diversity of sports included and the sample size do not enable a naïve generalisation of the current results (Jones et al., 2013). Future research might, therefore, be interested in studying the differences between the support offered by coaches and sport organisations to athletes suffering from MHIs across sports, levels, ages or/and gender. Finally, it is also probably worth commenting on the language used by us and the participants throughout the present manuscript. Although aware that some may see some stigma attached to certain terms such as "suffering from" or "issues", this was not our intention. This manuscript does not intend to stigmatize those who live with poor mental health, to the contrary.

\section{Acknowledgments}

The authors would like to thank the participants for their time and contribution.

Anderson, R. J., \& Pierce, D. (2012). Assumptions associated with mental health literacy training - Insights from initiatives in rural Australia. Advances in Mental Health, 10(3), 258-267. doi:10.5172/jamh.2012.10.3.258

Bengtsson, M. (2016). How to plan and perform a qualitative study using content analysis. NursingPlus Open, 2, 8-14. doi:10.1016/j.npls.2016.01.001

Braun, V., \& Clarke, V. (2006). Using thematic analysis in psychology. Qualitative Research in Psychology, 3(2), 77-101. doi:10.1191/1478088706qp063oa 
Cornford, C. S., Hill, A., \& Reilly, J. (2007). How patients with depressive symptoms view their condition: A qualitative study. Family Practice, 24(4), 358-364. doi:10.1093/fampra/cmm032

Doherty, S., Hannigan, B., \& Campbell, M. J. (2016). The experience of depression during the careers of elite male athletes. Frontiers in Psychology, 7(1069), 1-11. doi:10.3389/fpsyg.2016.01069

Ferguson, H. L., Swann, C., Liddle, S. K., \& Vella, S. A. (2018). Investigating youth sports coaches' perceptions of their role in adolescent mental health. Journal of Applied Sport Psychology, 31(2), 235-252. doi:10.1080/10413200.2018.1466839

Foundation, M. H. (2016). Fundamental facts about mental health 2016. Retrieved from https://www.mentalhealth.org.uk/publications/fundamental-facts-about-mental-health$\underline{2016}$

Gouttebarge, V., Backx, F. J. G., Aoki, H., \& Kerkhoffs, G. M. M. J. (2015). Symptoms of common mental disorders in professional football (soccer) across five European countries. Journal of Sports Science \& Medicine, 14(4), 811-818.

Gouttebarge, V., Hopley, P., Kerkhoffs, G., Verhagen, E., Viljoen, W., Wylleman, P., \& Lambert, M. (2018a). A 12-month prospective cohort study of symptoms of common mental disorders among professional rugby players. European Journal of Sport Science, 1-9. doi:10.1080/17461391.2018.1466914

Gouttebarge, V., Hopley, P., Kerkhoffs, G., Verhagen, E., Viljoen, W., Wylleman, P., \& Lambert, M. (2018b). A 12-month prospective cohort study of symptoms of common mental disorders among professional rugby players. European Journal of Sport Science, 18(7), 1004-1012. doi:10.1080/17461391.2018.1466914

Gouttebarge, V., Kerkhoffs, G., \& Lambert, M. (2016). Prevalence and determinants of symptoms of common mental disorders in retired professional Rugby Union players. 
European Journal of Sport Science, 16(5), 595-602. doi:10.1080/17461391.2015.1086819

Green, H., McGinnity, Á., Meltzer, H., Ford, T., \& Goodman, R. (2005). Mental health of children and young people in Great Britain, 2004. Retrieved from Office for National Statistics: https://digital.nhs.uk/data-and-information/publications/statistical/mentalhealth-of-children-and-young-people-in-great-britain/mental-health-of-children-andyoung-people-in-great-britain-2004

Gulliver, A., Griffiths, K. M., \& Christensen, H. (2012). Barriers and facilitators to mental health help-seeking for young elite athletes: A qualitative study. BMC Psychiatry, 12(1), 1-14. doi:10.1186/1471-244x-12-157

Gulliver, A., Griffiths, K. M., Mackinnon, A., Batterham, P. J., \& Stanimirovic, R. (2015). The mental health of Australian elite athletes. Journal of Science and Medicine in Sport, 18(3), 255-261. doi:10.1016/j.jsams.2014.04.006

Henriksen, K., Schinke, R., Moesch, K., McCann, S., Parham, William D., Larsen, C. H., \& Terry, P. (2019). Consensus statement on improving the mental health of high performance athletes. International Journal of Sport and Exercise Psychology, 1-8. doi:10.1080/1612197X.2019.1570473

Hill, A., MacNamara, Á., \& Collins, D. (2015). Psychobehaviorally based features of effective talent development in Rugby Union: A coach's perspective. The Sport Psychologist, 29(3), 201-212. doi:10.1123/tsp.2014-0103

Hill, A., MacNamara, Á., Collins, D., \& Rodgers, S. (2016). Examining the role of mental health and clinical issues within talent development. Frontiers in Psychology, 6(2042), 1-11. doi:10.3389/fpsyg.2015.02042

Jones, I., Brown, L., \& Holloway, I. (2013). Qualitative research in sport and physical activity. London: SAGE Publications Ltd. 
Jorm, A. F., \& Wright, A. (2008). Influences on young people's stigmatising attitudes towards peers with mental disorders: National survey of young Australians and their parents. The British Journal of Psychiatry, 192(2), 144-149. doi:10.1192/bjp.bp.107.039404

Jowett, S., \& Cockerill, I. M. (2003). Olympic medallists' perspective of the althlete-coach relationship. Psychology of Sport and Exercise, 4(4), 313-331. doi:10.1016/S14690292(02)00011-0

Kamm, R. L. (2008). Diagnosing emotional disorders in athletes: a sport psychiatrist's perspective. Journal of Clinical Sport Psychology, 2(2), 178 -201.

Kessler, R. C., Berglund, P., Demler, O., Jin, R., Merikangas, K. R., \& Walters, E. E. (2005). Lifetime prevalence and age-of-onset distributions of DSM-IV disorders in the national comorbidity survey replication. Archives of General Psychiatry, 62(6), 593602. doi:10.1001/archpsyc.62.6.593

Keyes, C. L. M. (2005). Mental illness and/or mental health? Investigating axioms of the complete state model of health. Journal of Consulting and Clinical Psychology, 73(3), $539-548$.

Klinkowski, N., Korte, A., Pfeiffer, E., Lehmkuhl, U., \& Salbach-Andrae, H. (2008). Psychopathology in elite rhythmic gymnasts and anorexia nervosa patients. European Child \& Adolescent Psychiatry, 17(2), 108-113. doi:10.1007/s00787-007-0643-y

Lauber, C., Nordt, C., Falcato, L., \& Rössler, W. (2003). Do people recognise mental illness? Factors influencing mental health literacy. European Archives Of Psychiatry And Clinical Neuroscience, 253(5), 248-251. doi:10.1007/s00406-003-0439-0

Lebrun, F., MacNamara, Á., Rodgers, S., \& Collins, D. (2018). Learning from elite athletes' experience of depression. Frontiers in Psychology, 9(2062), 1-11. doi:10.3389/fpsyg.2018.02062 
Livingston, J. D., Tugwell, A., Korf-Uzan, K., Cianfrone, M., \& Coniglio, C. (2013). Evaluation of a campaign to improve awareness and attitudes of young people towards mental health issues. Social Psychiatry and Psychiatric Epidemiology, 48(6), 965973. doi:10.1007/s00127-012-0617-3

Ltd., Q. I. P. (2015). NVivo Qualitative Data Analysis Software, Version 11.

MacNamara, Á., \& Collins, D. (2015). Profiling, exploiting, and countering psychological characteristics in talent identification and development. The Sport Psychologist, 29(1), 73-81. doi:10.1123/tsp.2014-0021

Mazzer, K. R., \& Rickwood, D. J. (2009). Community gatekeepers' advice to young people to seek help from mental health professionals: Youth workers and sport coaches. International Journal of Mental Health Promotion, 11(2), 13-23. doi:10.1080/14623730.2009.9721783

Mazzer, K. R., \& Rickwood, D. J. (2015a). Mental health in sport: Coaches' views of their role and efficacy in supporting young people's mental health. International Journal of Health Promotion and Education, 53(2), 102-114. doi:10.1080/14635240.2014.965841

Mazzer, K. R., \& Rickwood, D. J. (2015b). Teachers' and coaches' role perceptions for supporting young people's mental health: Multiple group path analyses. Australian Journal of Psychology, 67(1), 10-19. doi:10.1111/ajpy.12055

Newman, H. J. H., Howells, K. L., \& Fletcher, D. (2016). The dark side of top level sport: An autobiographic study of depressive experiences in elite sport performers. Frontiers in Psychology, 7(868), 1-12. doi:10.3389/fpsyg.2016.00868

Patel, V., Flisher, A. J., Hetrick, S., \& McGorry, P. (2007). Mental health of young people: A global public-health challenge. Lancet, 369(9569), 1302-1313. doi:10.1016/S01406736(07)60368-7 
810 Reardon, C. L., \& Factor, R. M. (2010). Sport psychiatry: A systematic review of diagnosis

811

812

813

814

815

816

817

818

819

820

821

822

823

824

825

826

827

828

829

830

831

832

833

834 and medical treatment of mental illness in athletes. Sports Medicine, 40(11), 961-980. doi:10.2165/11536580-000000000-00000

Reardon, C. L., Hainline, B., Aron, C. M., Baron, D., Baum, A. L., Bindra, A., . . . Engebretsen, L. (2019). Mental health in elite athletes: International Olympic Committee consensus statement (2019). British Journal of Sports Medicine, 53(11), 667-699. doi:10.1136/bjsports-2019-100715

Rice, S. M., Purcell, R., De Silva, S., Mawren, D., McGorry, P. D., \& Parker, A. G. (2016). The mental health of elite athletes: A narrative systematic review. Sports Medicine, 46(9), 1333-1353. doi:10.1007/s40279-016-0492-2

Ringland, A. (2016). Commentary: The experience of depression during the careers of elite male athletes. Frontiers in Psychology, 7(1869), 1-2. doi:10.3389/fpsyg.2016.01869

Roberts, C.-M., Faull, A. L., \& Tod, D. (2016). Blurred lines: Performance enhancement, common mental disorders and referral in the U.K. athletic population. Frontiers in Psychology, 7(1067), 1-13. doi:10.3389/fpsyg.2016.01067

Sabato, T. M., Walch, T. J., \& Caine, D. J. (2016). The elite young athlete: Strategies to ensure physical and emotional health. Open Access Journal of Sports Medicine, 7, 99113. doi:10.2147/OAJSM.S96821

Schaal, K., Tafflet, M., Nassif, H., Thibault, V., Pichard, C., Alcotte, M., . . Toussaint, J.-F. (2011). Psychological balance in high level athletes: Gender-based differences and sport-specific patterns. PLOS ONE, 6(5), 1-9. doi:10.1371/journal.pone.0019007

Schinke, R. J., Stambulova, N. B., Si, G., \& Moore, Z. (2017). International society of sport psychology position stand: Athletes' mental health, performance, and development. International Journal of Sport and Exercise Psychology, 16(6), 622-639. doi:10.1080/1612197X.2017.1295557 
835 Sebbens, J., Hassmén, P., Crisp, D., \& Wensley, K. (2016). Mental health in sport (MHS):

836

837

838

839

840

841

842

843

844

845

846

847

848

849

850

851 Improving the early intervention knowledge and confidence of elite sport staff. Frontiers in Psychology, 7(911), 1-9. doi:10.3389/fpsyg.2016.00911

Smith, B., \& McGannon, K. R. (2017). Developing rigor in qualitative research: problems and opportunities within sport and exercise psychology. International Review of Sport and Exercise Psychology, 1-21. doi:10.1080/1750984X.2017.1317357

Swann, C., Moran, A., \& Piggott, D. (2015). Defining elite athletes: Issues in the study of expert performance in sport psychology. Psychology of Sport and Exercise, 16, 3-14. doi:10.1016/j.psychsport.2014.07.004

Swann, C., Telenta, J., Draper, G., Liddle, S., Fogarty, A., Hurley, D., \& Vella, S. (2018). Youth sport as a context for supporting mental health: Adolescent male perspectives. Psychology of Sport and Exercise, 35, 55-64. doi:10.1016/j.psychsport.2017.11.008

Wolanin, A., Gross, M., \& Hong, E. (2015). Depression in athletes: Prevalence and risk factors. Current Sports Medicine Reports, 14(1), 56-60.

doi:10.1249/jsr.0000000000000123 
Table 1. TD Coaches' perception of their role, knowledge and needs regarding MHIs.

\begin{tabular}{cccc}
$\begin{array}{c}\text { Higher order } \\
\text { theme }\end{array}$ & $\begin{array}{c}\text { Third order } \\
\text { theme }\end{array}$ & $\begin{array}{c}\text { Second order } \\
\text { theme }\end{array}$ & $\begin{array}{c}\text { First order } \\
\text { theme }\end{array}$ \\
\hline
\end{tabular}



\begin{tabular}{|c|c|c|c|}
\hline TD Coaches' & $\begin{array}{l}\text { Perceived level of } \\
\text { knowledge and } \\
\text { understanding } \\
\text { regarding MHIs. }\end{array}$ & $\begin{array}{l}\text { Poor and/or } \\
\text { limited. } \\
\text { Moderate. }\end{array}$ & - \\
\hline $\begin{array}{l}\text { knowledge } \\
\text { about mental } \\
\text { health issues. }\end{array}$ & $\begin{array}{l}\text { Knowledge } \\
\text { acquisition. }\end{array}$ & $\begin{array}{l}\text { From formal } \\
\text { knowledge. } \\
\text { From personal } \\
\text { experiences. } \\
\text { From coaching } \\
\text { experiences. }\end{array}$ & - \\
\hline
\end{tabular}




\begin{tabular}{|c|c|c|c|}
\hline $\begin{array}{c}\text { Higher order } \\
\text { theme }\end{array}$ & $\begin{array}{c}\text { Third order } \\
\text { theme }\end{array}$ & $\begin{array}{l}\text { Second order } \\
\text { theme }\end{array}$ & $\begin{array}{c}\text { First order } \\
\text { theme }\end{array}$ \\
\hline \multirow{10}{*}{$\begin{array}{l}\text { Areas for } \\
\text { improvements. }\end{array}$} & \multirow{8}{*}{$\begin{array}{l}\text { Coaches' } \\
\text { identified needs. }\end{array}$} & Increasing coaches' & Increased awareness. \\
\hline & & knowledge about & Increased set of skills \\
\hline & & MHIs. & Context-specific approach. \\
\hline & & Increasing athletes' & Increased awareness. \\
\hline & & awareness about & Increased set of skills \\
\hline & & MHIs. & Use of role models \\
\hline & & Risks of mental & Over-cautious. \\
\hline & & health interventions. & Over-confident. \\
\hline & \multirow{2}{*}{$\begin{array}{l}\text { Requirements } \\
\text { for sport } \\
\text { environments }\end{array}$} & $\begin{array}{l}\text { More support for } \\
\text { coaches. }\end{array}$ & $\begin{array}{l}\text { Increasing the awareness on } \\
\text { coaches' MHIs. }\end{array}$ \\
\hline & & $\begin{array}{l}\text { Creation of a } \\
\text { support network } \\
\text { with health } \\
\text { professionals. }\end{array}$ & $\begin{array}{l}\text { Sport Psychologist. } \\
\text { Clinical Psychologist. }\end{array}$ \\
\hline
\end{tabular}

856 